\title{
LA TRANSFERENCIA TECNOLÓGICA EN EL ENTORNO EMPRESARIAL CUBANO
}

\author{
Coautores: Jorge Rondón Valdés ${ }^{1}$ \\ Alcides Antúnez Sánchez ${ }^{2}$
}

\section{RESUMEN:}

El fenómeno tecnológico emerge definitivo y determinante para el desarrollo científico-técnico de cualquier país, como reto y perspectiva en el entorno empresarial. La construcción de estrategias más funcionales, son garantes del avance tecnológico para la realización de su objeto social. Desde de la imposibilidad relativa de progreso científico-tecnológico endógeno, la transferencia de tecnologías deviene necesaria ante los pasos de una sociedad en vías de desarrollo. Su gradual evolución, ha devenido poco pertinente, en ocasiones descontextualizada su implementación para las empresas cubanas como receptoras de paquetes tecnológicos, para fundamentar la necesaria construcción de un proceso que armonice las demandas y realidades.

La investigación tiene como objetivo caracterizar la Transferencia Tecnológica en los procesos de contratación a partir del Derecho de la Propiedad Industrial en la inversión extranjera en la actualización del modelo económico social. Se utilizaron como métodos de investigación: el análisis lógico e histórico jurídico, análisis-síntesis, inductivo- deductivo, exegético jurídico y de derecho comparado. Los aportes de esta investigación permiten la construcción de marcos teóricos sustenten estrategias y procesos de transferencia tecnológica horizontales y pertinentes.

PALABRAS CLAVE: Empresa de alta tecnología, contratación, control público, desarrollo sostenible, economía basada en el conocimiento.

Recibido: 16 de julio 2018

Aprobado: 16 de agosto 2018

\footnotetext{
1 Profesor Auxiliar, contratado en la Universidad de Granma, Cuba, Licenciado en la Universidad de Oriente en 2005, profesor en el Departamento de Derecho desde 2005 hasta la actualidad, Imparte la signatura de Derecho Civil parte general, derecho de Obligaciones y Contratos. Especialista en Derecho Civil y Familia con mención en el ejercicio de la abogacía. Facultad de Derecho, Universidad de Oriente en 2013. Aspirante a Doctor. Autor de varios artículos publicados nacional e internacionalmente. Correo electrónico jrondonv@ udg.co.cu

2 Licenciado en Derecho. Máster en Asesoría Jurídica por la Universidad de Oriente. Profesor Auxiliar Derecho Ambiental. Facultad de Ciencias Económicas y Sociales. Contratado en la Universidad de Granma desde 2003 hasta la actualidad. República de Cuba. Trabajo investigativo resultado del Proyecto denominado "Consultoría Jurídica Rural", realizado en el 2016 en municipios de la provincia Granma por la Disciplina Derecho de la Empresa. Departamento de Derecho.Email: aantunez@udg.co.cu, antunez63@nauta.cu
} 


\title{
THE TECHNOLOGICAL TRANSFERENCE AT THE ENTREPRENEURIAL SURROUNDINGS CUBAN
}

\author{
Coauthors: Jorge Rondón Valdés* \\ Alcides Antúnez Sánchez **
}

\begin{abstract}
The technological phenomenon emerges definite and determining for the scientific technical development of any country, like challenge and perspective at the entrepreneurial surroundings. The construction of more functional strategies, they are responsible of the technological advance for the realization of his corporate purpose. From of the relative impossibility of scientific technological endogenous progress, the transference of technologies happens necessary in front of the steps of a developing society. His gradual evolution, has happened pertinent little, at times descontextualizada his implementation for the companies Cubans like recipients of technological parcels, to base the necessary construction of a process that harmonize the requests and realities.

The essay has like objective to characterize the Technological Transference in the processes of deal as from the right of the Industrial Property in the foreign investment in the bringing up to date of the social economic model. They utilized themselves like fact-finding methods: The logical and historic juridical analysis, analysis synthesis, inductive deductive, exegetic juridical and by right compared. The contributions of this investigation enable the construction of theoretic frames hold strategies and horizontal and pertinent processes of technological transference.
\end{abstract}

KEY WORDS: Company of high-tech, deal, public control, sustainable development, economy based in knowledge.

Received: July 16, 2018

Approved: August 16, 2018

\footnotetext{
*Assistant Professor, hired at the University of Granma, Cuba, graduated from the Universidad de Oriente in 2005, professor at the Department of Law from 2005 to the present, Imparts the Civil Law symbol, general part, right of Obligations and Contracts. Specialist in Civil Law and Family with mention in the practice of law. Faculty of Law, University of East in 2013. Aspiring Doctor. Author of several articles published nationally and internationally. Email jrondonv@udg.co.cu

** Degree in Law. Master in Legal Advice from the Universidad de Oriente. Assistant Professor Environmental Law. Faculty of economics and social sciences. Hired at the University of Granma from 2003 to the present. Republic of Cuba. Research work resulting from the Project called "Rural Legal Consultancy", carried out in 2016 in municipalities of Granma province by the Company Law Discipline. Department of Law. Email: aantunez@udg.co.cu, antunez63@nauta.cu
} 


\section{INTRODUCCIÓN}

En el contexto de un mundo globalizado y de la competencia internacional creciente, los gobiernos y los empresarios se preocupan cada vez más de su nivel tecnológico. En tal sentido, los procesos mediante los cuales se da la transferencia de tecnología entre los países son de gran importancia. En cambio, para los países subdesarrollados y en vías de desarrollo, con recursos tecnológicos menores, lo son aún más. Desde la necesidad de la construcción de un proceso que concilie las directivas centrales, (en tanto planificación por prioridades), con las necesidades tecnológicas de las empresas nacionales, desde el imperioso compromiso con lo local.

A partir de la verticalidad en la transferencia tecnológica, como el elemento limitante en la funcionabilidad de los procesos productivos, surge este ensayo, el que tiene como objeto el proceso de Transferencia de Tecnologías como generador de la Propiedad Intelectual, abrazando como objetivo: fundamentar la necesidad de la construcción de un proceso horizontal de Transferencia de Tecnologías que armonice con las demandas y realidades de los diferentes contextos empresariales.

De manera específica se pretende caracterizar los aspectos teórico-conceptuales de la Transferencia de Tecnologías. Sus formas y etapas, analizar los aspectos jurídico-contractuales de la Transferencia Tecnológica en el entorno empresarial estatal cubano; facilitando las bases metodológicas para la implementación de la Transferencia de Tecnologías, a partir de un proceso horizontal y comprometido con el contexto de la empresa cubana ${ }^{3}$. Como resultado de esta investigación emergen aportes que permitirán la construcción de marcos teóricos que sustenten estrategias y procesos horizontales pertinentes de transferencia tecnológica en el Derecho patrio.

3 LAGE, A. Las funciones de la ciencia en el modelo económico cubano, en Revista Temas, no. 69, Cuba, 2012, pp. 31-42.

\section{METODOLOGÍA}

Se utilizaron como métodos de investigación: el análisis lógico e histórico jurídico, análisis-síntesis, inductivo- deductivo, exegético jurídico y de derecho comparado. Los aportes de esta investigación permiten la construcción de marcos teóricos sustenten estrategias y procesos de transferencia tecnológica horizontales y pertinentes.

\section{LA TRANSFERENCIA TECNOLÓGICA}

Transferencia Tecnológica. Generalidades: acumulando su alcance de actividad e incluyendo el objetivo que persigue su pretendida funcionalidad, se han erigido en torno a la Transferencia de Tecnología numerosas definiciones. Según la definición de las Naciones Unidas, constituye un proceso de transmisión, absorción, adaptación, difusión y reproducción de la tecnología hacia una entidad distinta de donde se originó, la que como elemento distintivo puede ser onerosa o gratuita.

La regulación vigente en Cuba vinculada a los procesos de Transferencia de Tecnología, define la Transferencia de Tecnología como el proceso de transmisión, absorción, adaptación, difusión y reproducción de la tecnología hacia una entidad distinta a donde se originó.

En ambas definiciones está presente el concepto básico de la existencia de un ente emisor del conocimiento y un ente receptor del mismo como sujetos en esta relación jurídica contractual. Estas no se limitan, sin embargo, a aquellas transacciones que implican únicamente la venta de un producto.

La historia viene señalando que la transferencia de tecnología en América Latina y el Caribe (ALC) esta matizada por una dependencia hacia los países más avanzados y con un mayor desarrollo tecnológico y en materia de ciencias. Se importa la tecnología desde países desarrollados dado la escasez -en la región- del potencial de investigación y desarrollo, de la incapacidad de generar innovaciones y del 
robo de cerebros por parte de estos, entre otros aspectos. Esto provoca que se restinga la capacidad de generar conocimientos científicos y tecnológicos, o en general desarrollar la llamada "alta tecnología" en el sistema empresarial estatal cubano.

CASTRO DÍAZ-BALART y NÚÑEZ JOVER han reseñado que la ciencia, la tecnología y la innovación (CTI) son procesos sociales, sus aportes y aplicaciones se materializan en varias esferas de la sociedad, e implican más que teorías, productos y servicios. No obstante, su desarrollo no es equitativo y se aprecian considerables brechas entre los países desarrollados y subdesarrollados. La concentración del conocimiento en los países industrializados hace que los procesos de CTI no se orienten en solventar las demandas acuciantes de la sociedad, sino las de segmentos solventes del mercado.

Su Naturaleza jurídica es: pública, transfiere conocimientos científicos y/o tecnológicos y de tecnología.

Sujetos: personas naturales y jurídicas (comprador-receptor)

El desarrollo de la actividad según la forma de la actividad administrativa: contar con un adecuado sistema de información para el monitoreo de la tecnología existente, las regulaciones de propiedad intelectual, tecnología de competencia, bases jurídicas y políticas.

Ámbito de aplicación: sector empresarial privado y público.

Efectos: el desarrollo de innovaciones incrementales y menores sobre la tecnología adquirida, con el fin de mejorar productos, procesos productivos y así mantener la competitividad. La propagación y generalización de sus resultados.

Derivación de acciones del sistema de responsabilidad ambiental en distintos órdenes: civil, penal.
Relativa onerosidad de la actividad: costes del contrato por el pago del paquete tecnológico adquirido (hardware, software y orgware)

Formas de incorporación: la forma de tecnología incorporada (los equipos, procesos, productos), o de tecnología pura (know-how, patentes, marcas comerciales).

Elementos formales y de procedimiento: la adquisición de tecnología, asimilación, aprendizaje, difusión, formas de comercialización, flujos, mecanismos y estructuras de transferencia y el contrato.

Iniciativa de procedibilidad: los mecanismos de transferencia se ejecutan en programas de ayuda internacional y cooperación por parte del gobierno e instituciones; acuerdos de licencias (patentes, know-how, marcas); compraventa de maquinarias y equipos; entrenamientos y servicios de formación y capacitación del personal; joint ventures; proyectos llave en mano; asistencia técnica; inversiones extranjeras directas; spin-off y start-up.

Puntos de contacto con instituciones de otras ramas de la Ciencias Empresariales: derecho mercantil, derecho económico, derecho ambiental, derecho administrativo, Tic, auditoría, contabilidad, ciencias ambientales. Apreciado en las investigaciones realizadas en las instituciones universitarias con el proceso I+D+i, este comprende las investigaciones básicas, aplicadas, de desarrollo, innovativas y de generalización. Son el resultado de las necesidades sociales o del propio desarrollo de la ciencia y la tecnología, para generar o transferir conocimientos científicos-tecnológicos; los cuales se convierten en tecnologías de producto, procesos, organizacional, de servicios o sus combinaciones. Estas se realizan con el objetivo final de introducirlas en el sector productivo, contribuyendo a perfeccionar su desempeño económico y la competitividad de sus ofertas en los mercados nacionales e internacionales. 
La transferencia de tecnología, abordada por autores a partir del siglo XXI en Cuba, como CASTRO DÍAZ-BALART y NÚÑNEZ JOVER, han considerado los siguientes aspectos que la caracterizan como son:

- transferencia de conocimientos científicos y/o tecnológicos y de tecnología en sí, de un cedente a un receptor,

- adquisición, asimilación y difusión de la tecnología,

- direcciones que puede adoptar: transferencia vertical $^{4} \mathrm{u}$ horizontal ${ }^{5}$,

- flujos: de importación o exportación, y

- abarca más que la comercialización de un paquete tecnológico; consideran, además, el aprendizaje tecnológico.

Pero se razona, que la transferencia de tecnología en el proyecto social cubano en este siglo XXI podría definírsele como el proceso de intercambio racional, sustentable, inclusivo y colaborativo de conocimientos y/o tecnologías entre los actores sociales, donde se reflexiona que todo el proceso de creación del producto/servicio se negocian los principios de la adquisición, asimilación, y difusión; y los flujos, mecanismos y estructuras para transferir a través de procesos de aprendizaje mutuo y continuo.

Empero, los autores justiprecian que está necesitada de un estudio teórico que permita su regulación adecuada dentro del ordenamiento jurídico nacional, dada la importancia que tiene para el desarrollo económico de la nación.

Por ello, a pesar de que el conocimiento científico y tecnológico tiene una importancia clave, el conocimiento acerca de cómo organizar y gestionar las actividades económicas, especialmente aquellas que comprenden la aplicación de nuevas perspectivas científicas y tecnológicas, también es una determinante crucial del rendimiento económico

4 Vertical: se da en el contexto de un mismo país, donde los conocimientos endógenos se transforman y de ellos se apropian los agentes de la nación.

5 Horizontal: se da entre países, donde el país receptor la asimila en sus prácticas sociales. en una nación. Este progreso organizacional y de gestión se aprecia cómo está cobrando importancia a medida que aumenta el contenido científico y tecnológico de la actividad económica, que hoy viene señalando la necesaria implementación de la Responsabilidad Social Empresarial con la construcción de la empresa responsable.

La llamada sociedad basada en el conocimiento intenta resumir las nuevas tendencias de la producción, intercambio, cultura y en realidad de toda la vida cotidiana afectada por la difusión de diferentes paradigmas como las tecnologías de información, los cambios en la Biotecnología y las nuevas inversiones en investigaciones sobre Nanotecnología inciden en la redefinición de los mercados y en las relaciones públicas-privadas bajo la égida de la Administración Pública, aplicadas en la transferencia de tecnologías en la Empresa de Alta Tecnología.

\subsection{Clasificación. Etapas y modalidades:} la tecnología ha sido clasificada de forma multivariada, sin embargo, en relación a los de derechos de Propiedad Intelectual y a su significado mercantil y comercializable, básicamente encontramos que esta se clasifica en:

a. Tecnología Incorporada: está referida a bienes de capital en forma de maquinaria y equipos o recursos humanos mediante el entrenamiento local individual, expertos extranjeros, inmigrantes calificados, etc. o a bienes de consumo; y

b. Tecnología Desincorporada: que comprende resultados de investigaciones, nociones, datos, informaciones, habilidades, destrezas, así como también los métodos y las formas organizativas.

Ambas formas determinan derechos de Propiedad Intelectual. Las fases o etapas mediante las cuales transcurre la transferencia tecnológica, son:

1. Selección de la tecnología. 
2. Negociación (doc. contractual).

3. Absorción o Asimilación.

4. Adaptación.

5. Difusión.

6. Mejoras Tecnológicas.

Generalmente son reconocidas las siguientes modalidades de la transferencia de tecnologías:

- Transferencia horizontal de tecnología: proceso por el cual una tecnología es trasladada de un país a otro, flujo que se produce desde o hacia el exterior.

- Transferencia vertical de tecnología: proceso por el cual, dentro de un mismo país, se traslada tecnología de una institución a otra, en el marco de la interacción entre los entornos: productivo, tecnológico, científico y financiero, que interactúan entre sí y con el mercado durante el proceso de innovación.

Sin embargo, a pesar de encontrar mayores coincidencias en este tipo de clasificación de las modalidades a nivel internacional; con la autonomía de gestión y negociación empresarial en el mundo actual, se apuesta por un carácter puramente horizontal del proceso de transferencia tecnológica, necesitado dentro del ordenamiento jurídico cubano de un constructo desde la doctrina como se señalaba, donde se analice la norma jurídica y la práctica, que permita la evaluación de las tecnologías limpias; se justiprecia que hay una inadecuada participación de la Contraloría General de la República de Cuba en los procesos de incorporación de los avances tecnológicos del sector empresarial a los efectos de valorar su impacto ambiental con su implementación, en relación a los principio precautorio y de prevención, como más adelante será tratado en este ensayo jurídico ${ }^{6}$.

6 SANTA CRUZ RAMOS, A.L. Direito Empresarial Ezquematizado, Editorial Método, Brasil, 2010, pp. 95-157; SHARP JUNIOR, Ronald, Direito Comercial e de Empresa Sistematizado, Editorial Enselvier, Brasil, 2010, pp. 330-366; RABELO, Gabriel, Direito Empresarial, Editorial Método, Brasil, 2010, p.43.
En Cuba, COBO ROURA, ODRIOZOLA GUITART, RODRÍGUEZ COVIÁN, AGUILAR VILLÁN, MORENO CRUZ Y HORTA HERRERA han abordado los temas relacionados con el Derecho de la Empresa a partir del Derecho Económico, de la Propiedad Industrial, de la innovación biotecnológica, la protección de tecnologías, el secreto empresarial, las marcas, el diseño industrial, y la competencia desleal, entre otras temáticas incidentes en el tráfico mercantil para las personas naturales y jurídicas desde la Ciencia del Derecho, los que constituyen referentes a lo aquí señalado?

En el orden teórico, se constata que aún no han sido establecido los límites de la auditoría ambiental con la inspección ambiental como actividad de control, y sus lindes con la evaluación de impacto ambiental ante una insuficiente delimitación teórica y normativa con las Ciencias Empresariales y Ambientales, pertinente en la implementación de esta transferencia de tecnologías.

Hoy se aprecia que la tecnología que se implementa en la mayoría del sector empresarial cubano muestra altos signos de envejecimiento, obsolescencia y heterogeneidad industrial, con una data de más de medio siglo de explotación, elementos estos que no le permite ser en el siglo XXI competitiva en mercados foráneos con barreras comerciales exigentes, permiten señalar que la ausencia de una norma especial para la instrumentación de la auditoría ambiental incide en su no adecuada comprensión, asimilación y conocimiento pleno del papel que jugará en el sistema empresarial cubano y de su reconocimiento en relación con el tema abordado en una futura Ley de Empresas la transferencia de tecnologías y su adecuada implementación para el desarrollo sostenible.

7 A. A. Temas de Derecho Económico, Editorial Félix Varela, La Habana, 2005; MORENO CRUZ, M. y HORTA HERRERA, E. Selección de lecturas de Propiedad Industrial, Editorial Félix Varela, La Habana, 2005 


\section{ASPECTOS JURÍDICO-CONTRACTUALES EN EL ORDENAMIENTO JURÍDICO CUBANO}

En el mundo de hoy, el país, carente de capital, de determinadas tecnologías y hasta muchas veces de mercado, en aras de reestructurar su industria, amplió y facilitó el proceso de inversión extranjera en nuestra economía, teniendo como principio fundamental el respeto a la independencia y a la soberanía alcanzadas a través del proceso revolucionario que llevamos a cabo; lo que apoyaría de uno u otro modo en los esfuerzos que realiza el país en su desarrollo económico social, lo cual dio lugar a que necesariamente se propiciaran las inversiones privadas y foráneas.

La normativa nacional en el entorno empresarial cubano: los esfuerzos por aunar criterios estrechamente vinculados con la transferencia de tecnología, y a la vez estimados dentro de la economía basada en el conocimiento, la inversión, y la innovación constituyen un factor de amplia complejidad por las implicaciones que en todo el universo jurídico trae consigo. Las que necesitan de tener un adecuado control en su implementación, ponderando los principios del Derecho Ambiental y los del Derecho Administrativo ${ }^{8}$.

A continuación, se exponen las normas jurídicas más utilizadas y referidas por la literatura científica en la transferencia de tecnologías para el caso de Cuba, reguladas en el ordenamiento jurídico:

- Constitución de la República que establece en su Artículo 39: "El Estado orienta, fomenta y promueve la educación, la cultura y las ciencias en todas sus manifestaciones" especificando en sus apartados e) y f): e) La actividad creadora e investigativa en la ciencia es libre. El Estado estimula y viabiliza

8 ANTÚNEZ SÁNCHEZ, A. A auditoría ambiental dentro do Direito Ambiental. Os princípios do Direito Ambiental que a informam, papel da EFS na área ambiental, en Revista del Tribunal de Cuentas, Brasil, 2015. la investigación y prioriza la dirigida a resolver los problemas que atañen al interés de la sociedad y al beneficio del pueblo. f) El Estado propicia que los trabajadores se incorporen a la labor científica y al desarrollo de la ciencia?

- ElDecreto LeyNo. 68de1983, DeInvenciones, Descubrimientos Científicos, Modelos Industriales, Marcas y Denominaciones de Origen. Los artículos 184 y 185 del título XI, se refieren a la protección de Invenciones, Modelos Industriales y Marcas involucrados en el proceso de transferencia de tecnologías y establece restricciones en las negociaciones de activos intangibles a cumplir por los Organismos de la Administración Central del Estado ${ }^{10}$.

- Decreto No. 5 de 1977, Reglamento del Proceso Inversionista, que regula las funciones, obligaciones y relaciones de las diferentes entidades que intervienen en el proceso inversionista, entendiendo por inversiones solamente aquellas que, atendiendo a su estructura tecnológica, comprendan trabajos de construcción o montaje, con independencia del carácter productivo o no de la misma ${ }^{11}$.

- Decreto No. 105 de 1982, Reglamento para la evaluación y aprobación de las propuestas de inversión y de las tareas de inversión, es uno de los instrumentos que muestra un alcance amplio por referirse la cuestión inversionista, pero desconoce todo aquello que refiere al capital intelectual y sus derivaciones producidas como parte de la tecnología 12 .

9 Constitución de la República de Cuba, G.O. Extraordinaria No. 3 de fecha 31 de enero de 2003.

10 Decreto Ley No. 68, De Invenciones, descubrimientos científicos, modelos industriales, marcas y denominaciones de origen, G.O. Extraordinaria No. 10 de fecha 14 de mayo de 1983.

11 Decreto No. 5, Reglamento del Proceso Inversionista, G.O. Extraordinaria No. 4 de 23 de septiembre de 1997, modificado por el Decreto No. 327, Reglamento del proceso inversionista. G.O. Extraordinaria No. 5 de fecha 23 de enero de 2015.

12 Decreto No. 105, Reglamento para la evaluación y la aprobación 
- El Decreto No. 7 y No. 58 de 1989, establecen la reglamentación y funcionamiento de los comités de expertos, atribuyendo al Ministro de Ciencia, Tecnología y Medio Ambiente, la facultad de evaluar y dictaminar sobre la tecnología asociada a las inversiones del país ${ }^{13}$.

- El Acuerdo No. 2328, del Comité Ejecutivo del Consejo de Ministros de 1994, en su apartado segundo, numeral 6 , referido a las atribuciones y funciones del Ministerio de Ciencia, Tecnología y Medio Ambiente de establecer, de acuerdo con la política científica y tecnológica nacional, las normas técnicas, municipios y bases metodológicas para evaluar la importación y exportación de tecnologías y su impacto económico, social y ambiental ${ }^{14}$.

- La Resolución 13 de 1998 del CITMA, Requisitos básicos para la fundamentación, evaluación y dictamen de la transferencia de tecnología, asociada con los proyectos de inversión nominales propuestos en los estudios de factibilidad, que resulta de la asociación entre las inversiones y la tecnología como parte de la construcción teórico conceptual para acotar una posible variante de transferencia tecnológica. Esta establece que durante la etapa de preinversión los organismos inversionistas deberán de consultar al Ministerio de Ciencia, Tecnología y Medio Ambiente el estudio de factibilidad por el jefe de organismo antes de su presentación al Ministerio de Economía y Planificación para su evaluación y aprobación.

de las propuestas y tareas de inversiones, G.O. Ordinaria No. 41 de 19 de mayo de 1982.

13 Decreto No. 58, Reglamento evaluación y aprobación de proyectos técnicos, G.O.O. de 27 de diciembre de 1979.

14 Acuerdo No. 2328, del Comité Ejecutivo del Consejo de Ministros, de 25 de noviembre de 1994.
- La Resolución No 14 de 2001, que establece el procedimiento para desarrollar el proceso de negociación, presentación de solicitudes y evaluación de las propuestas de Inversión Extranjera.

- Resolución 126 de 2007, pone en vigor el Procedimiento para la Evaluación de los Estudios de Factibilidad de las Inversiones vinculadas a las esferas de la ciencia, la tecnología y medio ambiente.

Estas normativas jurídicas, valoran los autores que aún y cuando representan un avanzado paso hacia la implementación de la Transferencia Tecnológica, padecen en su mayoría un marcado carácter tecnologicista, amén del fin sociocultural de la economía y el desarrollo tecnológico, necesitadas de un adecuado constructo desde la doctrina como se ha venido citando en el ensayo dentro del ordenamiento jurídico ${ }^{15}$.

Pretiriendo la valuación necesaria de sectores populares, donde también se implementan los paquetes tecnológicos: instituyen la verticalidad legal, que a pesar de organizar relaciones de subordinación, arroja como resultado la imposibilidad autónoma directa de las empresas para establecer vínculos de transferencia tecnológica a partir de sus necesidades endógenas, pues al pasar por un mecanismo escalonado, instrumental, engorroso y bastante largo, corren el riesgo de desestimación al someterse a una evaluación a diferentes instancias que dispondrán finalmente la pertinencia de lo que ellas mismas deben conocer mejor que nadie ${ }^{16}$.

Prosiguiendo el íter de lo señalado, la actividad de control a través de la inspección o de la auditoría, son herramientas de gestión importantes para realizar la evaluación de su impacto y ponderar los principios

15 ROMANO,S. El ordenamiento jurídico, trad. de la 2da edición efectuada por Sebastián Martin Retortillo y Lorenzo MartínRetortillo, Instituto de Estudios Políticos, Madrid, 1963.

16 PÉREZ, C. Las nuevas tecnologías: una visión de conjunto, en C. Ominami (Ediciones) La Tercera Revolución Industrial, Grupo Editor Latinoamericano RIAL, Buenos Aires, 1986, pp.43- 89. 
precautorio, prevención, legalidad y responsabilidad, tal y como se ha señalado por ANTÚNEZ SÁNCHEZ, y RAMÍREZ SÁNCHEZ en sus estudios sobre esta temática en el Derecho cubano ${ }^{17}$.

\section{TRANSFERENCIA TECNOLÓGICA HORIZON- TAL Y CONTEXTUALIZADA. UN RETO PARA LA ECONOMÍA CUBANA}

3.1. Tecnología y Desarrollo: Es imposible hablar de tecnología, sin detenerse en la finalidad que la determina, en tanto deviene en mejoras, perfeccionamiento, especialización, evolución; esta finalidad que persigue un futuro próspero y perfeccionado, se ha llamado por comunidad internacional: Desarrollo. Después de la Revolución Industrial ${ }^{18}$, con la consolidación de la ciencia moderna, construida a partir de los siglos XVI y XVII, surgió el "modo clásico" de desarrollo, el cual presenta las siguientes características:

- universalidad de la "tecnología" y de los modelos para su transferencia y adopción;

- visión mecánica de la realidad, donde la metáfora de una máquina sine para comprender el funcionamiento del mundo; y

- neutralidad del proceso de desarrollo, a partir de la creencia de que el método científico mantiene alejados los valores e intereses humanos.

17 ANTÚNEZ SÁNCHEZ, A. y RAMIREZ SÁNCHEZ, A. Actualización del modelo económico cubano para el ordenamiento jurídico en el desarrollo del Derecho Ambiental patrio, en Revista Multiciencias, no. 3, Venezuela, 2015, p. 1-27; La Ley No. 81 de 1997, dispone que toda actividad susceptible de producir efectos significativos sobre el medio ambiente o que requiera de un debido control a los efectos del cumplimiento de lo establecido por la legislación ambiental, está sujeta al otorgamiento de una licencia ambiental por el Ministerio de Ciencia, Tecnología y Medio Ambiente de conformidad con lo que al respecto estipule este organismo.

18 MENDEZ GUTIERREZ DEL VALLE, R. Teoría de las revoluciones industriales, tres son revoluciones, la primera en la industria metalúrgica y textil, la segunda con el motor de explosiónexplosivos químicos, la industria del automóvil, la industria siderúrgica y la producción de aparatos eléctricos, la tercera con la biotecnología, la microelectrónica y la informática -1800-2007- en, Revista del Ministerio de Fomento, España, 2009, pp.7-29.
Existen diferentes contextos según el modo de desarrollo, estos se superponen gradual y evolutivamente. DE SOUZA SILVA expone tres tipos de estos escenarios de donde emergen respectivas revoluciones. Nos habla de una revolución económica, liderada por el mercado y que establece un nuevo régimen de acumulación y representación del capitalismo global ; una revolución tecnológica bajo el comando de la máquinas y la que consideramos más completa: una revolución cultural que; cuestionando las premisas de la civilización occidental, bajo una visión contextual del mundo; crea un escenario bajo el orden de una sociedad que asume el mundo como una trama de relaciones y significados entre diferentes formas y modos de vida, promoviendo así la relevancia de lo humano, lo social, lo cultural, lo ecológico y lo ético.

Indudablemente la tecnología engloba el proceso mediante el que los hombres perfilan instrumentos y máquinas para agrandar su control y comprensión de la naturaleza y de su entorno material.

Pero su definición no se reduce a ese talante, si pensáramos así, estaríamos marginando los medulares aspectos relacionados con el hombre, su cultura y las motivaciones de su conocimiento. De ahí que nos es indispensable encauzar el avance tecnológico comulgando con las premisas de una revolución cultural, que apueste por el progreso y transfiera tecnologías al interior de su tejido empresarial y social-sistémico, persiguiendo el desarrollo con una visión humanocéntrica.

El país se orienta hacia esta finalidad, pero en el transcurso de sus intentos y esfuerzos, su propia normativa y planificación directriz se han alejado de ese fin primigenio, reflejando de manera silente el verdadero resultado que persigue la tecnología en el entramado de las relaciones sociales donde se gesta y es, finalmente, introducida ${ }^{19}$.

19 NÚÑEZ JOVER, J. y MONTALVO ARRIETE, L. La politica de ciencia, tecnología e innovación en la actualización del modelo económico cubano: evaluación y propuestas en, Revista Economía y Desarrollo, No. 2, Universidad de La Habana, 2013, pp. 40-53. 


\subsection{El modelo vertical de transferencia} tecnológica: Al asumir como necesidad una economía planificada, Cuba tuvo que arrostrar los retos y consecuencias que resultan de este fenómeno. La existencia de la centralización en una república unitaria, establece como núcleo central la capital y sus instituciones como el centro económico y de poder más relevante de toda la nación.

De ahí que el rol de las instituciones científicas (centro de investigación, polos científico-técnicos y centros académicos) en su papel de facilitadoras del desarrollo, convierten, recurrentemente, sus propuestas en el fin de su empeño y no en el medio para orientar el desarrollo. Por esta razón, se trata de generalizar, la transferencia de paquetes tecnológicos, que a su consideración representan prioridad, según las condicionantes de ese contexto urbano $^{20}$.

A partir de esta noción, las empresas que lideran tecnológicamente, se ven en la necesidad de adoptar paquetes tecnológicos que, según las prelaciones establecidas en las direcciones nacionales, resultan precisas y viables en razón de su implementación. Entonces se produce una ruptura entre la realidad de los contextos empresariales, y las directrices que prevalecen. Los trámites de negociación, la conciliación según motivaciones de la empresa, y la satisfacción a demandas de la propia sociedad, son remplazadas por necesarias orientaciones, que con carácter administrativo se superponen indefectiblemente.

Esta verticalidad de la transferencia tecnológica tiene un trasfondo internacional mucho más grave, pues a pesar de existir cierta negociabilidad en la gestión de tecnologías foráneas, prima un principio de sabiduría discriminativa en el que, a pesar, de los contratos de asistencia técnica, el know-how, licencias de patentes, y las licencias de marcas de bienes y/o servicios; impera una estrategia capitalista 20 INFANTE UGARTE, J. La empresa estatal socialista cubana y su transformación competitiva en, Revista electrónica Cofín Habana, No 4, ANEC, La Habana, 2014, pp-84-94. de liderazgo científico-técnico sobre los receptores, creando intencionadamente una dependencia determinada por el consumo que se asienta en patrones de la moda y del avance tecnológico. Los países subdesarrollados, se convierten en consumidores diarios de paquetes tecnológicos ${ }^{21}$ transferidos que casi nunca terminan con mejoras o innovaciones para las naciones, y el ciclo amenaza con sacralizarse irrevocablemente ${ }^{22}$.

Cuando la transferencia de tecnologías busca, comprometidamente, una solución a los problemas que se plantean en la sociedad, y lo hace relacionando la ciencia (el campo de los conocimientos científicos) y la técnica (sus conocimientos, herramientas y capacidad inventiva) con la estructura económica y sociocultural del medio (las formas organizativas, los modos de producción, el marco cultural, entre otros aspectos) entonces se está en presencia de un modo puramente horizontal de transferencia tecnológica ${ }^{23}$.

\subsection{Descongestión de los canales de} acceso: Los mecanismos nacionales de acceso a la aprobación institucional para la transferencia de tecnologías, está demasiado congestionado de trámites administrativos, alejándose vertiginosamente de las realidades de los entornos empresariales y los actores que involucra; se prevén estudios de factibilidad, que son presentados y sometidos a comités de expertos en las delegaciones del Ministerio de Ciencias, Tecnología y Medio Ambiente ${ }^{24}$, sólo para empresas con

21 Decreto-Ley No 313, de la Zona Especial de Desarrollo Mariel, G.O. Extraordinaria No. 26 de septiembre 2013.

22 Ley No. 118, Ley de la Inversión Extranjera, G.O. Extraordinaria No. 20, de fecha 16 de abril de 2014.

23 LAGE, A. Las funciones de la ciencia en el modelo económico cubano, en Revista Temas, No. 69, Cuba, 2012, pp. 31-42; ANTÚNEZ SÁNCHEZ, A. La empresa de alta tecnología. Una visión desde el Derecho en, Revista Legis, Foro de Derecho Mercantil, Colombia, 2016.

24 Ley No. 81, De Medio Ambiente. G.O. Extraordinaria No.7 de fecha 11 de julio de 1997, en relación a velar por la implementación de los resultados de la Evaluación Ambiental Estratégica realizada por el Ministerio de Ciencia, Tecnología y Medio Ambiente en los 
aprobación de inversión extranjera; luego de este paso se presenta ante el Ministerio de Economía y Planificación ${ }^{25}$ que evalúa nueva y rigurosamente, y finalmente aprueba.

Y ahora con la Contraloría General de la República ${ }^{26}$, que también ejecutará acciones de control a través de la auditoría, hoy ausente en su desarrollo práctico por parte del órgano de control.

De tal forma que, con el ánimo de incentivar nuevas investigaciones, que abracen el reto de preservar las conquistas sociales obtenidas, y viajar a las interioridades de las necesidades de progreso tecnológico de nuestra sociedad socialista, cabría preguntarse:

- ¿Qué sucederá si en el transcurso de estos trámites sobreviene la obsolescencia de la tecnología en cuestión?

- ¿Qué ocurre con las empresas que no están en la dinámica de inversión directa, o no son empresas mixtas, en cuanto a la negociación de la tecnología a transferir?

- ¿Cómo se satisfacen las necesidades de empresas con tecnologías incipientes?

- ¿Qué posibilidades decisorias tienen los directivos, empresarios y gerentes, para suscribir con empresas de capital foráneo, contratos de transferencia tecnológica con mecanismos de aprobación más simples?

Finalmente, si se construye un proceso en virtud del cual: teniendo como base un conocimiento previo $y$ el impulso de una exigente o gradual necesidad proyectos que se aprueben para la Zona de Desarrollo Industrial, como se aprecia se excluye a la Contraloría General de la República con la auditoría ambiental.

25 Decreto Ley No. 147, De la reorganización de los OACE. G. O. Extraordinaria No.2 de fecha 21 de abril de1994; Ley No. 118, Ley de la Inversión Extranjera. G. O. Extraordinaria No. 20 de fecha 16 de abril de 2014.

26 Ley No. 107, de la Contraloría General de la República de Cuba. G.O. Ordinaria No. 29 de fecha 14 de agosto de 2009. En relación a la práctica de la auditoría ambiental para la evaluación de las nuevas tecnologías; ANTUNEZ SÁNCHEZ, A. La auditoría ambiental en el Derecho Público, (sin publicar), 2016. de la empresa, se concibe y aplican nuevas ideas, objetos y formas tecnológicas que conducen a cambios útiles, que a su vez deben sostener una armonía con los factores socioculturales, ambientales y espirituales que informan la vida de las entidades, comunidades y localidades donde se introducen; estaremos en presencia de un proceso de Transferencia Tecnológica que convive con las necesidades de su contexto y apuesta por el desarrollo endógeno de su entorno empresarial y de la sociedad en sentido general, será logrado con la empresa responsable, que pondere el desarrollo sostenible ${ }^{27}$.

En atención al referente de CASTRO DÍAZ-BALART al señalar que la empresa de base tecnológica: donde la tecnología constituye un elemento básico de diferenciación y la empresa es capaz de gestionarla en beneficio del negocio propio frente a los competidores y en armonía con el resto de sus funciones estratégicas, generando ventajas competitivas sostenidas ${ }^{28}$.

\section{CONCLUSIONES}

Las investigaciones realizadas acerca del tema, proyectaron aspectos conclusivos que servirán de incentivo a próximos estudios y acercamientos a los asuntos desarrollados en este trabajo.

- La Transferencia de Tecnología surge como necesidad de lograr el desarrollo de una empresa pública, un grupo científico-social, o de un país en sentido general. Presentándose como un proceso complejo, con modalidades independientes, clasificaciones con sus particularidades, y una secuencia de etapas.

27 ANTÚNEZ SÁNCHEZ, A. Los principios del Derecho Ambiental que informan la auditoría ambiental en su aplicación por la Entidad Fiscalizadora Superior en Cuba, en Revista De Jure, no. 1, Guadalajara, 2015; ANTÚNEZ SÁNCHEZ, A. La auditoría ambiental: Una revisión y propuestas en clave de su función pública y dimensión empresarial, en Revista Iberoamericana de Contabilidad de Gestión, no. 26, Universidad Autónoma de Madrid, España, 2015.

28 CASTRO DÍAZ-BALART F. Amanecer del tercer milenio. Ciencia, tecnología y sociedad. Editorial Debate, España, 2002 
- La legislación nacional, ha ido atemperando una normatividad jurídica en materia de Transferencia Tecnológica, pero ha instituido mecanismos de engorroso acceso, con trámites numerosos y exigentes, que prevalecen sobre el contexto donde se implementan los paquetes tecnológicos, deviniendo cuestionable su pertinencia en la actualización del modelo económico social en el desarrollo de la inversión extranjera.

- El modo clásico de desarrollo propio del capitalismo, tendente a la mercantilización irracional de tecnologías; ha minado el mundo contemporáneo, imponiendo una filosofía del consumo tecnológico que desdice de procesos complejos donde conviven las relaciones de utilidad y los patrones culturales de las sociedades donde se implementan.

- La construcción de un proceso horizontal y contextualizado de Transferencia Tecnológica entraña primero: paliar el protagonismo hegemónico de los grandes focos tecnológicos internacionales, persiguiendo la generación de innovaciones tecnológicas de manera endógenay; segundo: establecerinternamente métodos flexibles de negociación que desembaracen los mecanismos de acceso a la transferencia tecnológica y se supediten en relaciones de utilidad y funcionalidad según las realidades socioculturales de los contextos empresariales cubanos.

\section{BIBLIOGRAFÍA}

- AA. VV. Libre mercado y protección ambiental. Intervención y orientación ambiental de las actividades económicas, en SANZ LARRUGA, I. (coordinador), Editorial Instituto Nacional de Administración Pública, Madrid, 2011, p. 117 y ss.

- AA. W. Temas de Derecho Mercantil cubano, tomos I-II, Editorial Félix Varela, La Habana, 2005.
- AA. VV. La inversión extranjera y de la Unión Europea en Cuba, Centro de Estudios de la Economía cubana, Universidad de La Habana, Cuba, 2012.

- ATIENZA, M., Curso de argumentación jurídica, Editorial Trotta, Madrid, 2013.

- ANTÚNEZ SÁNCHEZ, A. La empresa de alta tecnología. Una visión desde el Derecho en, Revista Legis Foro de Derecho Mercantil, Colombia, 2016.

- ANTÚNEZ SÁNCHEZ, A. Actualización del modelo económico cubano para el ordenamiento jurídico en el desarrollo del Derecho Ambiental patrio en, Revista Multiciencias, no. 3, Venezuela, 2015, p. 1-27.

- ANTÚNEZ SÁNCHEZ, A. Los principios del Derecho Ambiental que informan la auditoría ambiental en su aplicación por la Entidad Fiscalizadora Superior en Cuba en, Revista De Jure, no. 1, Guadalajara, 2015.

- BARCELÓ LLAUGER, M. Hacia una economía del conocimiento, Editorial ESIC, Madrid, 2001.

- BARRRERA GRAF, J. Derecho Mercantil, $1^{\text {ra }}$ edición, Editorial UNAM, México, 1991, pp.77-92.

- BAYOS, H. Tratado de Derecho Industrial, Editorial Civitas, Madrid, 1978.

- BARBOSA PIMENTEL, Carlos, Direito Empresarial, 8 ${ }^{\text {va }}$ edición, Editorial Elservier, Brasil, 2010, pp.41-50.

- BROSETA PONT, M. y MARTíneZ SANZ, F. Manual de Derecho Mercantil, Editorial Tecnos, Madrid, 2010.

- CASTILLO VITLLOCH, A.; CABALLERO TORRES, I.; LAGE DÁVILA, A. Modelo de gestión económica de la empresa estatal socialista de alta tecnología a la luz de los Lineamientos del VI Congreso del Partido Comunista de Cuba, en Revista Economía y Desarrollo, no. 2, Universidad de La Habana, Cuba, 2012, pp. 94-123. 
- CAStRO díAZ-BALART, F. Ciencia, innovación $y$ futuro, Editorial Grijalbo Mandadori, Barcelona, 2002.

- CASTRO DÍAZ-BALART F. Amanecer del tercer milenio. Ciencia, tecnología y sociedad. Editorial Debate, España, 2002.

- CABAL MIRABAL, C. y RODRígueZ CASTELLANOS, C. Una visión de la ciencia en Cuba. Pasos y Caminos en, Revista Anales de la Ciencia en Cuba, no. 5, La Habana, 2015.

- CABAL, C. La ciencia cubana componente del patrimonio cultural de la nación, en Revista Anales de la Academia de Ciencias de Cuba, La Habana, 2014.

- CAÑIZARES ABELEDO, F. Derecho Comercial, Editorial Ciencias Sociales, La Habana, 2012.

- CRUZ RODRÍGUEZ, V. EI Derecho como barrera o catalizador de los procesos de innovación rural: una visión a favor del desarrollo rural cubano, Universidad de Granma, 2010.

- CARRERAS, M. Reglamentación jurídica de la propiedad industrial. Primer seminario sobre derechos de autor, propiedad industrial $y$ transferencia de tecnología, Editorial UNAM, México, 2004.

- CONTRERAS, C. Transferencia de tecnología a países en desarrollo, Editorial Instituto Latinoamericano de Investigaciones Sociales S.A. Lima, 2003.

- COOPER, R. The dimensions of industrial new product success and failure, Editorial Journal of Marketing, Oslo, 2005.

- DÁVALOS FERNÁNDEZ, R. Las empresas mixtas. Regulación jurídica, 2da Edición, Consultoría Jurídica Internacional, La Habana,1993.

- DÁVALOS FERNÁNDEZ, R. Fronteras y contratos. Derecho aplicable al contrato internacional, Editorial Ciencias Sociales, La Habana, 2005.

- DE SOUZA SILVA, J. ¿Quo Vadis Innovación Institucional? La Innovación de la Innovación, del cambio de las cosas al cambio de las personas que cambian las cosas. Red Nuevo Paradigma para la Innovación Institucional en América Latina, División ISNAR del IFPRI, Costa Rica, 2006.

- ETZKOWITZ, H. Innovation in Innovation: The Triple Helix of University-Industry-Government Relations. Social Science Information, no. 42, Estados Unidos de América, 2003, pp. 293-337.

- ESTEVE PARDO, J. De la policía administrativa a la gestión de riesgos, en Revista Española de Derecho Administrativo, no. 119, España, 2003.

- PAREjO AlfONSO, L. El Derecho ante la innovación y los riesgos derivados del cambio climático, Editorial Tiran lo Blanch, España, 2015.

- PÉREZ, C. Las nuevas tecnologías: una visión de conjunto, en C. Ominami (Ediciones) La Tercera Revolución Industrial, Editorial Latinoamericano RIAL, Buenos Aires, 1986, pp.43- 89.

- PEÑASOLÍS, J. La actividad de laAdministración Pública: de policía administrativa, de servicio público, de fomento y de gestión económica, Manual de Derecho Administrativo, Volumen 3, Colección de Estudios Jurídicos del Tribunal Supremo, Venezuela, 2003.

- RABELO, G. Direito Empresarial, Editorial Método, Brasil, 2010, p.43.

- RíOS GUAL, J. La reingeniería aplicada al mundo empresarial del siglo XXI en, Revista de Empresas, España, 2007.

- LAGE, A. Las funciones de la ciencia en el modelo económico cubano, en Revista Temas, no. 69, Cuba, 2012, pp. 31-42.

- LEMARCHAND, G. Las políticas de ciencia, tecnología e innovación en América Latina y el Caribe durante las últimas seis décadas. Red de Información en Política Científica (SPIN), Oficina Regional de Ciencia de la UNESCO para América Latina y el Caribe, 2010, p.132, Disponible en: http://spin.unesco.org. uy (Consultada 20 septiembre 2016).

- LE RIVERAND, J. Acerca de la historia económica de Cuba: fuentes y orientaciones, 
Editorial Ciencias Sociales Contemporáneas, La Habana, 1965, pp.23-50.

- LIBRO VERDE, Marco europeo para la responsabilidad social de las empresas, Comisión de las Comunidades Europeas, Bruselas, 2003.

- MATIlla CORREA, A. Notas sobre la ley y el principio de legalidad en el ordenamiento jurídico cubano, en AA. VV. en, Memorias del VI Foro Iberoamericano de Derecho Administrativo, VIII Jornadas de Derecho Constitucional y Administrativo, Universidad Externado de Colombia, Bogotá, 2007.

- MORÁN MARTíNEZ, L. La Propiedad Industrial en los Acuerdos de Transferencia de Tecnología, Editorial OCPI, La Habana, 2002.

- MORENO CRUZ, M. y HORTA HERRERA, E. Selección de Lecturas de Propiedad Industrial, Editorial Félix Varela, La Habana, 2005.

- MÉNDEZ GUTIERREZ DEL VALLE, R. Teoría de las Revoluciones Industriales, Ministerio de Fomento, España, 2009.

- NUÑEZ JOVER, J. La Ciencia y la Tecnología como procesos sociales. Lo que la educación científica no debería olvidar, $2^{\text {da }}$ edición, Editorial Félix Varela, La Habana, 2007.

- NUÑEZ JOVER, J. La política de ciencia, tecnología e innovación tecnológica en Cuba: evaluación y propuestas, Editorial Félix Varela, La Habana, 2015.

- NúÑ̃Z JOVER, J. y MONTALVO ARRIETE, L. La política de ciencia, tecnología e innovación en la actualización del modelo económico cubano: evaluación y propuestas en, Revista Economía y Desarrollo, no. 2, Universidad de La Habana, Cuba, 2013, pp. 40-53.

- Organización de las Naciones Unidas para la Educación, la Ciencia y la Cultura. Hacia las sociedades del conocimiento. Informe mundial de la UNESCO, 2005, Disponible en: http://www.unesco.org/publications

- INFANTE UGARTE, J. La empresa estatal socialista cubana y su transformación competitiva en, Revista electrónica Cofín Habana, no. 4, La Habana, 2014, pp-84-94.
- INFORME del 7mo Congreso del Partido Comunista de Cuba, Editorial Empresa Gráfica de Holguín, Cuba, 2016.

- SANTA CRUZ RAMOS, A. Direito Empresarial Ezquematizado, Editorial Método, Brasil, 2010, pp. 95-157.

- SÁNCHEZ CALERO, F. Instituciones de Derecho Mercantil, en Revista de Derecho Privado, España, 1995.

- SALAS COUCE, C. La inversión extranjera directa en Cuba. Situación actual y propuesta de política, en Revista Análisis Económico, no. 51, México, 2007.

- SORIANO GARCÍA, J. EI Derecho Administrativo y los desafíos del siglo XXI, Editorial Aranzadi, España, 2011, pp. 1-29.

- SHARP JUNIOR, R. Direito Comercial e de Empresa Sistematizado, Editorial Enselvier, Brasil, 2010, pp. 330-366.

- PAREJO ALFONSO, L. El derecho ante la innovación y los riesgos derivados del cambio climático, $1^{\text {ra }}$ edición, Editorial Tirand lo Blanch, España, 2015.

- PRIETO VALDÉS, M. El ordenamiento jurídico cubano, Editorial Félix Varela, La Habana, 2003, pp.143-149.

- tRIANA, J. Economía Basada en el Conocimiento. In TECNOGEST'2009, XI Encuentro Nacional Gestión del conocimiento y empresas de alto desempeño. Disponible en: URL:\10.12.1.64\docs\PSI\PreGrado Comunicación Social\Disciplina Gerencia y Mercadotecnia\Mercado y Tecnologíal Bibliografía|TECNOGEST

- KLINE, Stephen J. An Overview of innovation. Editorial National Academy Press. Washington, 1999.

- URIA, R. Derecho Mercantil, Tomo I-II, Editorial Félix Varela, Cuba, 2008.

- VALLS, J. Tecnología e innovación en la empresa. Dirección y gestión. Editorial UPS. Navarra, 2000. 
- VEGA PEÑA, Y. Los Acuerdos de Licencia en la transferencia de tecnologías para la comercialización de activos intangibles de Propiedad Intelectual. Universidad de Oriente, Cuba, 2007.

- VILLAR PALASÍ, J. La actividad administrativa industrial del Estado en el Derecho Administrativo en, Revista de Administración Pública, número 3, España, 1950. 